\title{
Associations between blood eosinophils and decline in lung function among adults with and
}

without asthma

Robert J. Hancox ${ }^{1}$, Ian D Pavord ${ }^{2}$, Malcolm R. Sears ${ }^{3}$.

1. Department of Preventive and Social Medicine, Dunedin School of Medicine, University of Otago, Dunedin, New Zealand.

2. Respiratory Medicine Unit and Oxford NIHR Biomedical Research Centre, Nuffield Department of Medicine, University of Oxford, Oxford, UK.

3. Firestone Institute for Respiratory Health, Michael de Groote School of Medicine, McMaster University and St Joseph's Healthcare, Hamilton, Ontario, Canada.

Correspondence: Professor R. J. Hancox, Dept of Preventive and Social Medicine, Dunedin School of Medicine, University of Otago, Dunedin 9054, New Zealand Telephone: $\quad+6434798512$

email: $\quad$ bob.hancox@ otago.ac.nz

Take Home Message: Blood eosinophils are associated with lung function decline even in people without asthma or wheeze.

Author contributions: R.J.H. developed the hypothesis for this analysis with input from M.R.S. and I.D.P. M.R.S. and R.J.H collected the data. R.J.H. analysed the data and drafted the manuscript. All authors provided critical review of the manuscript and approved its submission. Sources of Support: The Dunedin Multidisciplinary Health and Development Research Unit is funded by the Health Research Council of New Zealand. Duke University (USA) provided additional funding for respiratory data collection at age 38 .

Word count: 2997 


\begin{abstract}
Eosinophilic inflammation and airway remodelling are characteristic features of asthma, but the association between them is unclear. We assessed associations between blood eosinophils and lung function decline in a population-based cohort of young adults.
\end{abstract}

We used linear mixed models to analyse associations between blood eosinophils and spirometry at $21,26,32$, and 38 years adjusting for sex, smoking, asthma, and spirometry at age 18 . We further analysed associations between mean eosinophil counts and changes in spirometry from ages 21 to 38 years.

Higher eosinophils were associated with lower $\mathrm{FEV}_{1} / \mathrm{FVC}$ ratios and lower percent-predicted $\mathrm{FEV}_{1}$ values for both pre- and post-bronchodilator spirometry (all $\mathrm{p}$ values $\leq 0.048$ ). Although eosinophil counts were higher in participants with asthma, the associations between eosinophils and spirometry were similar among participants without asthma or wheeze. Participants with mean eosinophil counts $>0.4 \times 10^{9} / \mathrm{L}$ between ages 21 and 38 had greater declines in $\mathrm{FEV}_{1} / \mathrm{FVC}$ ratios $(1.8 \% ; 95 \% \mathrm{CI} 0.7,2.9 ; \mathrm{p}=0.001)$ and $\mathrm{FEV}_{1}$ values $(3.4 \%$ predicted; $95 \% \mathrm{CI} 1.5,5.4)$; $\mathrm{p}=0.001)$ than those with lower counts.

Blood eosinophils are associated with airflow obstruction and enhanced decline in lung function independently of asthma and smoking. Eosinophilia is a risk factor for airflow obstruction even in those without asthma or symptoms.

\footnotetext{
Abstract words: 200
} 


\section{Introduction}

Eosinophilic airway inflammation and airway remodelling leading to persistent airflow obstruction are characteristic features of asthma, but the link between them is unclear.[1] Although tissue eosinophils are associated with remodelling of the airway wall, it has not been established whether this is a causal association.[2-4] Controlling eosinophilic inflammation with inhaled corticosteroids reduces exacerbations, [5-7] but has not yet been shown to prevent the development of fixed airflow obstruction.[1]

One reason for the uncertainty is that measurement of eosinophilic airway inflammation using induced sputum is unsuitable for routine clinical practice or large-scale epidemiological studies.[7, 8] Peripheral blood eosinophil counts have emerged as a promising and easily measured marker of eosinophilic airway inflammation.[9-12] High blood eosinophils are associated with poor asthma control and risk for exacerbations.[13-15] Blood eosinophil counts also predict the response to inhaled corticosteroids in patients with COPD,[16-18] and the response to anti-IL5 therapy in asthma.[19] Blood eosinophil counts have been associated with lower $\mathrm{FEV}_{1}$ values in participants with and without asthma,[13, 20-23] but not all studies have found this.[24] Blood eosinophils did not predict an enhanced decline in $\mathrm{FEV}_{1}$ in asthmatic adults, $[22,25,26]$ but a greater decline in $\mathrm{FEV}_{1}$ was observed in COPD patients with high blood eosinophil counts who were not treated with inhaled corticosteroids.[18]

We investigated associations between blood eosinophil counts and lung function in a populationbased birth cohort of young adults. We hypothesised that eosinophilic inflammation would be associated with airflow obstruction and a decline in lung function among participants with asthma. 


\section{Methods}

The Dunedin Multidisciplinary Health and Development Study is a longitudinal investigation of health and behaviour in an unselected population-based cohort of individuals born in the only maternity hospital in Dunedin in 1972/73 (http://dunedinstudy.otago.ac.nz).[27, 28] The cohort was formed when 1,037 children living in the greater Dunedin area (91\% of eligible births) were assessed at age 3 years. Study members represent the full range of socio-economic status in the South Island of New Zealand and are primarily of New Zealand/European ethnicity. The study has a high rate of follow-up: $95 \%$ of living study members participated in the most recent assessment at age 38. Written informed consent was obtained for each assessment. The Otago Ethics Committee approved the study.

Childhood asthma was defined as a parent-reported diagnosis of asthma with compatible symptoms or asthma medication within the previous year at 9, 11, or 13 years.[28] Adult asthma was defined as a self-reported diagnosis with compatible symptoms or medication within the previous year at ages $21,26,32$, or 38 years. Wheeze included all episodes of reported wheeze in the previous year, excluding only one or two episodes lasting less than one hour.[27] Inhaled corticosteroid use was recorded at each age. Current smoking was defined as daily smoking for at least one month in the previous year. Cumulative tobacco exposure was quantified in packyears (equivalent to 20 cigarettes/day for one year).[28]

At ages 21, 26, 32, and 38 years, blood was drawn at the end of the assessment day. Eosinophil counts were obtained from automated complete blood counts and were reported to two decimal places at ages 21,26 , and 32 but to one decimal place at age 38 . Eosinophil counts $>0.4 \times 10^{9} / \mathrm{L}$ were regarded as high.[15]

Spirometry was performed at ages $18,21,26,32$, and 38 years. This was repeated after inhaled salbutamol at 18, 26, 32, and 38.[28] Height was measured at each assessment. Skin-prick tests 
for 11 common aeroallergens were done at ages 21 and 32.[29] Participants were considered to have atopic sensitisation if they had at least one positive test (weal diameter $\geq 2 \mathrm{~mm}$ greater than negative control) at either age.

\section{Statistical analyses}

We compared sex, asthma, atopy, smoking, and lung function at age 38 among those with and without complete eosinophil data. Non-parametric (Spearman) correlations, intraclass correlations and the persistence of high $\left(>0.4 \times 10^{9} / \mathrm{L}\right)$ counts between ages were used to assess the consistency of eosinophil counts between ages.

Eosinophil counts were transformed with natural logarithms to approximate normal distributions. To allow transformation of zero values, 0.1 was added before transformation and later deducted from the geometric mean values. Linear mixed models were used to assess predictors of log-eosinophil counts with fixed effects for age and a random effect for participants to accommodate repeated measurements. These models included current smoking, childhood asthma, adult asthma, atopic sensitisation, inhaled corticosteroid use, and sex as predictors.

Linear mixed models with fixed effects for age and a random effect for participants were also used to assess whether log-eosinophil counts were associated with airflow obstruction. The primary outcome measure was the pre-bronchodilator $\mathrm{FEV}_{1} / \mathrm{FVC}$ ratio from ages 21 to 38 years. Secondary outcome measures were percent predicted $\mathrm{FEV}_{1}$ and FVC and post-bronchodilator spirometry.[30] Analyses adjusted for spirometry measurements at age 18, sex, childhood and adult asthma, inhaled corticosteroids, and pack-years. Analyses tested for interactions between eosinophils and asthma diagnoses. Additional separate analyses were done for those with and without adult asthma. Body Mass Index (BMI) is associated with lower $\mathrm{FEV}_{1} / \mathrm{FVC}$ ratios among women in this cohort [31] and because atopic sensitisation was associated with higher eosinophil counts, further analyses adjusted for these factors. We also tested for interactions between 
eosinophils and smoking. The models were repeated with adjustment for childhood and adult wheeze instead of diagnosed asthma. Spirometry data were approximately normally distributed and were not transformed before analysis. Models were checked by inspection of histograms of residuals and scatterplots of residuals against fitted values.

To further assess whether eosinophil counts were associated with decline in lung function, changes in $\mathrm{FEV}_{1} / \mathrm{FVC}$ ratio and $\mathrm{FEV}_{1}$ from age 21 to 38 years were plotted with respect to the mean eosinophil counts across these ages. Changes in lung function were compared between those with and without mean eosinophil counts $>0.4 \times 10^{9} / \mathrm{L}$ using t-tests.

Analyses used Stata 13 (College Station, TX). Spirometry from pregnant women and one implausible measurement were excluded. Otherwise, analyses used all available data. Two-sided $\mathrm{p}$ values $<0.05$ were considered statistically significant.

\section{Results}

Characteristics of the participants are shown in Table 1. Those who missed at least one blood sample had similar rates of asthma, atopy, and $\mathrm{FEV}_{1} / \mathrm{FVC}$ ratios, but were more likely to smoke and had lower FEV $\mathrm{F}_{1}$ values (Online Table 1). Geometric mean eosinophil counts at each age are shown in Table 2.

Eosinophil counts differed between ages (Wald $\mathrm{p}<0.001$ ): counts were higher at age 21 than older ages (all pairwise $\mathrm{p} \leq 0.001$ ) but were not significantly different between ages 26,32 , and 38 (all pairwise $\mathrm{p} \geq 0.054$ ). Twenty-one-year-olds did not have higher eosinophils when these were expressed as a percentage of total leukocytes. Among 691 participants who had eosinophils measured at all four assessments, geometric mean (95\% CI) eosinophil counts were $0.25(0.23$, 
$0.27) \times 10^{9}$ cells/L for those with adult asthma and $0.17(0.17,0.18) \times 10^{9}$ cells/L for those without (t-test $\mathrm{p}<0.001)$.

Spearman correlations between counts at each age are shown in Table 2. Correlations were similar among those with and without asthma (Online Table 2). The interclass correlation coefficient for individual eosinophil counts was $0.58(\mathrm{p}<0.001)$ over the 17-year follow-up. High eosinophils (>0.4 x109 cells /L) were found in 193 of 961 measurements (20\%) among 269 participants with adult asthma and 200/2424 measurements (8\%) among 701 participants without (chi-square $\mathrm{p}<0.001$ ). Among those with high eosinophils, the count remained high at the next measurement for $52 \%$ of those with asthma and $42 \%$ of those without. For participants with complete eosinophil data, 81/201 (40\%) of those with asthma and 96/490 (20\%) without asthma had at least one count above $0.4 \times 10^{9}$ cells /L (chi-square $\left.\mathrm{p}<0.001\right)$, but only $13(6 \%)$ of those with asthma and $5(1 \%)$ of those without had high counts at every assessment (chi-square $\mathrm{p}<0.001)$. Thirty-five $(17 \%)$ of those with asthma and $30(6 \%)$ of those without had mean eosinophil counts $>0.4 \times 10^{9}$ cells $/ \mathrm{L}$ across the four tests (chi-square $\mathrm{p}<0.001$ ).

Childhood and adult asthma, atopic sensitisation, current smoking, and inhaled corticosteroid use were associated with higher eosinophil counts (Table 3). Smokers did not have higher eosinophils when these were expressed as a percentage of total leukocytes (Online Table 3).

Eosinophil counts were associated with lower pre- and post-bronchodilator $\mathrm{FEV}_{1} / \mathrm{FVC}$ ratios and $\mathrm{FEV}_{1}$ values (Table 4). There were no interactions between adult asthma and eosinophil counts for any spirometry measure (all interaction $\mathrm{p} \geq 0.359$ ): when analysed separately, eosinophil counts were associated with lower $\mathrm{FEV}_{1} / \mathrm{FVC}$ ratios and $\mathrm{FEV}_{1}$ values among those with and without asthma, although these associations were not statistically significant for postbronchodilator $\mathrm{FEV}_{1}$. Adjustments for atopic sensitisation and BMI made no material difference 
to the analyses (not shown). There were no interactions between current or cumulative smoking and eosinophil counts for any spirometry measure (all interaction $\mathrm{p} \geq 0.166$ ).

Eosinophil counts were associated with lower pre- and post-bronchodilator $\mathrm{FEV}_{1} / \mathrm{FVC}$ ratios and $\mathrm{FEV}_{1}$ values in analyses adjusting for wheeze and for pre-bronchodilator values in the subgroups with and without wheeze. Post-bronchodilator $\mathrm{FEV}_{1} / \mathrm{FVC}$ ratios and $\mathrm{FEV}_{1}$ values were only significantly associated with eosinophils among those reporting wheeze although there was a tendency $(\mathrm{p}=0.081)$ for an association with lower $\mathrm{FEV}_{1} / \mathrm{FVC}$ ratios among those without wheeze (Table 5).

Scatterplots of the associations between mean eosinophil counts and the changes in $\mathrm{FEV}_{1} / \mathrm{FVC}$ ratios and $\mathrm{FEV}_{1}$ values between ages 21 and 38 are shown in the figure. The coefficients of the fitted regression lines were not different for those with and without asthma (interaction $\mathrm{p}$ values $\geq 0.638$ ) and were statistically significant for both groups (all $p$ values $\leq 0.033$ ). Participants with mean eosinophil counts $>0.4 \times 10^{9} / \mathrm{L}$ had mean excess declines of $1.8 \%$ in $\mathrm{FEV}_{1} / \mathrm{FVC}(95 \% \mathrm{CI}$ : $0.7,2.9 \% ; \mathrm{p}=0.002)$ and $3.3 \%$ in predicted $\mathrm{FEV}_{1}(95 \% \mathrm{CI}: 1.3,5.3 ; \mathrm{p}=0.001)$ between ages 21 and 38 compared to those with lower eosinophil counts. By comparison, those who smoked $\geq 10$ pack-years had mean excess declines of $2.4 \%$ in $\mathrm{FEV}_{1} / \mathrm{FVC}(95 \% \mathrm{CI}: 1.6,3.2 \%$; $\mathrm{p}<0.001)$ and $3.5 \%$ in predicted $\mathrm{FEV}_{1}(95 \% \mathrm{CI}: 2.0,4.9 ; \mathrm{p}<0.001)$.

\section{Discussion}

In this population-based cohort of young adults, blood eosinophil counts were associated with lower $\mathrm{FEV}_{1} / \mathrm{FVC}$ ratios and lower $\mathrm{FEV}_{1}$ values. These associations were found for both pre- and post-bronchodilator measurements and were independent of childhood or adult asthma diagnoses, cumulative smoking exposure, and lung function measured at the beginning of 
adulthood. Higher eosinophil counts were also associated with a greater decline in $\mathrm{FEV}_{1} / \mathrm{FVC}$ ratios and $\mathrm{FEV}_{1}$ values. The declines in $\mathrm{FEV}_{1}$ and $\mathrm{FEV}_{1} / \mathrm{FVC}$ among those with high mean eosinophil counts across the four assessments were of a similar magnitude to the declines observed among those who smoked 10 pack-years or more over the same time. The findings demonstrate that blood eosinophilia is associated with airflow obstruction and indicate that it may be an important risk factor for lung function decline.

As far as we are aware, this is the first study to explore longitudinal associations between blood eosinophils and lung function in a general population sample. Although participants with asthma had higher mean eosinophil counts, blood eosinophil counts were associated with worse lung function and similar declines in $\mathrm{FEV}_{1}$ and $\mathrm{FEV}_{1} / \mathrm{FVC}$ among participants with and without asthma and even among those who did not report wheezing symptoms. This suggests that eosinophilic inflammation contributes to lung function decline and airflow obstruction even among those without diagnosed airway disease or relevant symptoms. This is consistent with evidence from some cross-sectional studies that high blood eosinophil counts are associated with lower $\mathrm{FEV}_{1}$ values in non-asthmatics.[20, 21, 23] although this was not observed in the large NHANES III study.[24] Findings from previous longitudinal research on eosinophils and lung function have been inconsistent. $[22,23,26,32]$ The largest study found that although blood eosinophils were associated with lower $\mathrm{FEV}_{1}$ values at baseline among adults with asthma, they did not predict lung function decline over 12 years,[22] while a post hoc analysis of the placebo arm of an inhaled corticosteroid trial found that COPD patients with high blood eosinophils had a more rapid decline in $\mathrm{FEV}_{1 .[18]}$ Differences in the characteristics of the populations studied, cut-offs for defining high blood eosinophils, and potential treatment responses may explain some of the inconsistencies between these studies. 
We used blood eosinophils as a marker of airway eosinophilic inflammation. Studies of lung function decline and direct makers of airway eosinophilia are limited to smaller asthmatic cohorts and the findings are inconsistent. One study found that neither blood nor sputum eosinophils predicted $\mathrm{FEV}_{1}$ decline over 5 years in difficult to treat asthma,[25] whereas a study of asthmatics with fixed airflow obstruction found that sputum eosinophils predicted 5-year $\mathrm{FEV}_{1}$ decline.[33] Another study found that patients who had experienced a rapid decline in FEV $_{1}$ over 8 years had higher blood and sputum eosinophils.[34] The variability in sputum eosinophils counts, rather than persistently high levels, was found to be associated with a greater decline in $\mathrm{FEV}_{1}$ over 6 years in patients with refractory asthma.[35] Bronchial biopsy studies have found that lung function decline is associated with inflammatory changes, including the numbers of CD4 and CD8 positive cells, but not with eosinophils.[34, 36, 37] These inconsistencies may also be due to differences in the characteristics of the asthmatic sub-groups studied and potential treatment responses, as well as small sample sizes and the difficulties in directly measuring airway inflammation.

As this is an observational study, we cannot prove that eosinophilic inflammation causes airflow obstruction or whether this could be prevented with treatment. Sputum eosinophil counts are associated with asthma exacerbations and treatment with inhaled corticosteroids reduces this risk,[5-7] but the finding that blood eosinophils were associated with lower lung function among participants without either asthma or wheeze makes it highly unlikely that the association can be explained by recurrent asthma exacerbations among those with high blood eosinophils.

Our findings suggest that long-term eosinophilic airway inflammation may worsen lung function decline and increase the risk for COPD. This is important because it may be possible to prevent this with treatment. A post hoc analysis of the ISOLDE study found that inhaled fluticasone appeared to reduce the decline in $\mathrm{FEV}_{1}$ in COPD patients with high blood eosinophils.[18] We 
need information from prospective randomised controlled trials to establish whether treating eosinophilic inflammation with inhaled corticosteroids would improve long-term outcomes for lung function in either COPD or asthma.[1, 38]

Few factors are known to cause lung function decline among healthy young adults: only exposure to pollutants (including tobacco smoke) has been consistently found to lead to airflow obstruction at a population level. Our findings suggest that eosinophilic inflammation may be another factor, and this effect appears to be independent of asthma. The drivers of this inflammation are unknown but it is plausible that exposure to environmental or occupational allergens contribute to this. Atopic sensitisation was not an independent predictor of lung function, however, and adjusting the analyses for atopic sensitisation made no material difference to the findings. Higher BMI has been found to be associated with lower FEV $1 / F V C$ ratios in women in this cohort,[31] but was not associated with eosinophil counts and adjusting the analyses for BMI did not alter the findings for either sex.

Blood eosinophils were moderately correlated between ages. This is consistent with previous reports, $[10,22]$ and extends the period of observation to 17 -years and to young adults with and without asthma. There was considerable variability around our pre-specified cut point of $0.4 \times 10^{9}$ cells/L. Variability around this and other cut points has been noted in other studies, indicating that a single test is insufficient to characterise long-term eosinophilia.[39] As anticipated, atopic sensitisation and asthma were associated with higher counts. In keeping with other observations,[32] we found that smokers had higher absolute eosinophils counts than nonsmokers but this could be explained by higher total leukocyte counts. Total leukocyte and eosinophil counts were also higher at age 21 years than older ages, but percentage eosinophil counts were similar. We analysed absolute eosinophil counts as recommended,[40] but repeating the analyses using percentage eosinophils made no material differences to the findings. 
The study has a number of strengths including measurements of eosinophils and spirometry on four occasions over 17 years with a high rate of follow-up. We adjusted for many potential covariates or effect modifiers including childhood and adult asthma, symptoms of wheeze, smoking exposure, and spirometry at age 18 . There are also some limitations, however. Peripheral blood eosinophil counts are only a proxy measure of airway eosinophilia, although obtaining direct measurements of airway eosinophils in this large epidemiological study would be unfeasible with current techniques. Asthma diagnoses were self-reported and this may have led to some misclassification. We do not have post-bronchodilator measures of lung function at age 21. Participants who missed one or more blood samples were more likely to smoke and had slightly lower $\mathrm{FEV}_{1}$ values, but restricting the analyses to those who had eosinophil counts at every age made no material difference to the findings. Eosinophils counts were only reported to one decimal place $\left(\times 10^{9} / \mathrm{L}\right)$ at age 38 , but restriction of the analyses to ages 21 to 32 also made little difference to the findings. So far, we have only followed the cohort to early mid-adult life and we cannot extrapolate the findings to older adults or the risk for clinically diagnosed COPD.

The implications for clinical practice are not yet clear. We need to know the long-term risk of developing COPD among people with high blood eosinophil counts and whether antiinflammatory treatment alters this risk. The finding that blood eosinophils are associated with airflow obstruction in people without asthma or wheeze raises questions about the role of asymptomatic eosinophilia. Could eosinophils allow us to identify asymptomatic individuals at high risk of developing chronic lung disease and facilitate targeted prevention strategies? We also need to understand more about the intrinsic and environmental drivers of eosinophilic inflammation and whether these are amenable to intervention at individual or population-based levels. 
In summary, we have found that blood eosinophil counts are moderately stable across young adult life and that high counts are associated with airflow obstruction. Although eosinophil counts were higher in participants with asthma, associations between blood eosinophil counts and airflow obstruction were present in those without asthma or symptoms of wheeze. The findings suggest that persistent blood eosinophilia is an independent risk factor for the development of airflow obstruction even in those without respiratory disease.

\section{Acknowledgements}

We are grateful to the study members and their friends and families for their continued support. We thank the respiratory physiologists and interviewers who obtained the measurements and $\mathrm{Mr}$ Andrew Gray who provided statistical advice. We also thank the Professor Richie Poulton, the study director, Dr Phil A Silva, the study founder, and Professors Terrie Moffitt and Avshalom Caspi for their support. M Sears holds the AstraZeneca chair in Respiratory Epidemiology at McMaster University. 


\section{References}

1. Saglani S, Lloyd CM. Novel concepts in airway inflammation and remodelling in asthma. Eur Respir J 2015: 46: 1796-1804.

2. Wenzel SE, Schwartz LB, Langmack EL, Halliday JL, Trudeau JB, Gibbs RL, Chu HW. Evidence that severe asthma can be divided pathologically into two inflammatory subtypes with distinct physiologic and clinical characteristics. Am J Respir Crit Care Med 1999: 160: 10011008.

3. Wilson SJ, Rigden HM, Ward JA, Laviolette M, Jarjour NN, Djukanović R. The relationship between eosinophilia and airway remodelling in mild asthma. Clin Exp Allergy 2013: 43: 1342-1350.

4. Elliot JG, Jones RL, Abramson MJ, Green FH, Mauad T, Mckay KO, Bai TR, James AL. Distribution of airway smooth muscle remodelling in asthma: Relation to airway inflammation. Respirology 2014: 20: 66-72.

5. Green RH, Brightling CE, McKenna S, Hargadon B, Parker D, Bradding P, Wardlaw AJ, Pavord ID. Asthma exacerbations and sputum eosinophil counts: a randomised controlled trial. Lancet 2002: 360: 1715-1721.

6. Jayaram L, Pizzichini MM, Cook RJ, Boulet LP, Lemiere C, Pizzichini E, Cartier A, Hussack P, Goldsmith CH, Laviolette M, Parameswaran K, Hargreave FE. Determining asthma treatment by monitoring sputum cell counts: effect on exacerbations. Eur Respir J 2006: 27: 483-494.

7. Petsky HL, Cates CJ, Lasserson TJ, Li AM, Turner C, Kynaston JA, Chang AB. A systematic review and meta-analysis: tailoring asthma treatment on eosinophilic markers (exhaled nitric oxide or sputum eosinophils). Thorax 2012: 67: 199-208.

8. Davies AR, Hancox RJ. Induced sputum in asthma: diagnostic and therapeutic implications. Curr Opin Pulm Med 2013: 19: 60-65. 
9. Yap E, Chua WM, Jayaram L, Zeng I, Vandal AC, Garrett J. Can we predict sputum eosinophilia from clinical assessment in patients referred to an adult asthma clinic? Intern Med $J$ 2013: 43: 46-52.

10. Katz LE, Gleich GJ, Hartley BF, Yancey SW, Ortega HG. Blood eosinophil count is a useful biomarker to identify patients with severe eosinophilic asthma. Ann Am Thorac Soc 2014: 11: 531-536.

11. Zhang X-Y, Simpson JL, Powell H, Yang IA, Upham JW, Reynolds PN, Hodge S, James AL, Jenkins C, Peters MJ, Lin J-T, Gibson PG. Full blood count parameters for the detection of asthma inflammatory phenotypes. Clin Exp Allergy 2014: 44: 1137-1145.

12. Wagener AH, de Nijs SB, Lutter R, Sousa AR, Weersink EJM, Bel EH, Sterk PJ. External validation of blood eosinophils, FENO and serum periostin as surrogates for sputum eosinophils in asthma. Thorax 2015: 70: 115-120.

13. Schleich FN, Chevremont A, Paulus V, Henket M, Manise M, Seidel L, Louis R. Importance of concomitant local and systemic eosinophilia in uncontrolled asthma. Eur Respir J 2014: 44: 97-108.

14. Tran TN, Khatry DB, Ke X, Ward CK, Gossage D. High blood eosinophil count is associated with more frequent asthma attacks in asthma patients. Ann Allergy Asthma Immunol 2014: 113: 19-24.

15. Price DB, Rigazio A, Campbell JD, Bleecker ER, Corrigan CJ, Thomas M, Wenzel SE, Wilson AM, Small MB, Gopalan G, Ashton VL, Burden A, Hillyer EV, Kerkhof M, Pavord ID. Blood eosinophil count and prospective annual asthma disease burden: a UK cohort study. Lancet Respir Med 2015: 3: 849-858.

16. Bafadhel M, McKenna S, Terry S, Mistry V, Pancholi M, Venge P, Lomas DA, Barer MR, Johnston SL, Pavord ID, Brightling CE. Blood eosinophils to direct corticosteroid 
treatment of exacerbations of chronic obstructive pulmonary disease: a randomized placebocontrolled trial. Am J Respir Crit Care Med 2012: 186: 48-55.

17. Pascoe S, Locantore N, Dransfield MT, Barnes NC, Pavord ID. Blood eosinophil counts, exacerbations, and response to the addition of inhaled fluticasone furoate to vilanterol in patients with chronic obstructive pulmonary disease: a secondary analysis of data from two parallel randomised controlled trials. Lancet Respir Med 2015: 3: 435-442.

18. Barnes NC, Sharma R, Lettis S, Calverley PMA. Blood eosinophils as a marker of response to inhaled corticosteroids in COPD. Eur Respir J 2016: 47: 1374-1382.

19. Pavord ID, Korn S, Howarth P, Bleecker ER, Buhl R, Keene ON, Ortega H, Chanez P. Mepolizumab for severe eosinophilic asthma (DREAM): a multicentre, double-blind, placebocontrolled trial. Lancet 2012: 380: 651-659.

20. Ulrik CS. Eosinophils and pulmonary function: an epidemiologic study of adolescents and young adults. Ann Allergy Asthma Immunol 1998: 80: 487-493.

21. Lewis SA, Pavord ID, Stringer JR, Knox AJ, Weiss ST, Britton JR. The relation between peripheral blood leukocyte counts and respiratory symptoms, atopy, lung function, and airway responsiveness in adults. Chest 2001: 119: 105-114.

22. Nadif R, Boudier A, Moual Nl, Just J, Gormand F, Pison C, Matran R, Pin I. Blood granulocyte patterns as predictors of asthma phenotypes in adults from the EGEA study. Eur Respir J 2016: 48: 1040-1051.

23. Frette C, Annesi I, Korobaeff M, Neukirch F, Dore MF, Kauffmann F. Blood eosinophilia and FEV1. Cross-sectional and longitudinal analyses. Am Rev Respir Dis 1991: 143: 987-992.

24. McKeever T, Saha S, Fogarty AW. The association between systemic inflammatory cellular levels and lung function: a population-based study. PLOS ONE 2011: 6: e21593. 
25. van Veen IH, Ten Brinke A, Sterk PJ, Sont JK, Gauw SA, Rabe KF, Bel EH. Exhaled nitric oxide predicts lung function decline in difficult-to-treat asthma. Eur Respir J 2008: 32: 344-349.

26. Ulrik CS, Backer V, Dirksen A. A 10 year follow up of 180 adults with bronchial asthma: factors important for the decline in lung function. Thorax 1992: 47: 14-18.

27. Sears MR, Greene JM, Willan AR, Wiecek EM, Taylor DR, Flannery EM, Cowan JO, Herbison GP, Silva PA, Poulton R. A longitudinal, population-based, cohort study of childhood asthma followed to adulthood. N Engl J Med 2003: 349: 1414-1422.

28. Hancox RJ, Gray AR, Poulton R, Sears MR. The Effect of Cigarette Smoking on Lung Function in Young Adults with Asthma. Am J Respir Crit Care Med 2016: 194: 276-284.

29. Hancox RJ, Welch D, Poulton R, Taylor DR, McLachlan CR, Greene JM, Sears MR. Cigarette smoking and allergic sensitization: a 32-year population-based cohort study. J Allergy Clin Immunol 2008: 121: 38-42 e33.

30. Hankinson JL, Odencrantz JR, Fedan KB. Spirometric reference values from a sample of the general U.S. population. Am J Respir Crit Care Med 1999: 159: 179-187.

31. Sutherland TJT, Mclachlan CR, Sears MR, Poulton R, Hancox RJ. The relationship between body fat and respiratory function in young adults. Eur Respir J 2016: 48: 734-747. 32. Taylor RG, Joyce H, Gross E, Holland F, Pride NB. Bronchial reactivity to inhaled histamine and annual rate of decline in FEV1 in male smokers and ex-smokers. Thorax 1985: 40: 9-16.

33. Contoli M, Baraldo S, Marku B, Casolari P, Marwick JA, Turato G, Romagnoli M, Caramori G, Saetta M, Fabbri LM, Papi A. Fixed airflow obstruction due to asthma or chronic obstructive pulmonary disease: 5-year follow-up. J Allergy Clin Immunol 2010: 125: 830-837. 
34. Broekema M, Volbeda F, Timens W, Dijkstra A, Lee NA, Lee JJ, Lodewijk ME, Postma DS, Hylkema MN, ten Hacken NHT. Airway eosinophilia in remission and progression of asthma: accumulation with a fast decline of FEV(1). Respir Med 2010: 104: 1254-1262. 35. Newby C, Agbetile J, Hargadon B, Monteiro W, Green R, Pavord I, Brightling C, Siddiqui S. Lung function decline and variable airway inflammatory pattern: longitudinal analysis of severe asthma. J Allergy Clin Immunol 2014: 134: 287-294.

36. van Rensen ELJ, Sont JK, Evertse CE, Willems LNA, Mauad T, Hiemstra PS, Sterk PJ, Group AS. Bronchial CD8 cell infiltrate and lung function decline in asthma. Am J Respir Crit Care Med 2005: 172: 837-841.

37. den Otter I, Willems LNA, van Schadewijk A, van Wijngaarden S, Janssen K, de Jeu RC, Sont JK, Sterk PJ, Hiemstra PS. Lung function decline in asthma patients with elevated bronchial CD8, CD4 and CD3 cells. Eur Respir J 2016: 48: 393-402.

38. Pavord ID, Lettis S, Locantore N, Pascoe S, Jones PW, Wedzicha JA, Barnes NC. Blood eosinophils and inhaled corticosteroid/long-acting $\beta$-2 agonist efficacy in COPD. Thorax 2016: 71: $118-125$.

39. Rabe KF, Beghé B, Fabbri LM. Peripheral eosinophil count as a biomarker for the management of COPD: not there yet. Eur Respir J 2017: 50.

40. Szefler SJ, Wenzel S, Brown R, Erzurum SC, Fahy JV, Hamilton RG, Hunt JF, Kita H, Liu AH, Panettieri RA, Schleimer RP, Minnicozzi M. Asthma outcomes: biomarkers. J Allergy Clin Immunol 2012: 129: S9-23. 


\section{Figure legend.}

Scatter plots of changes in $\mathrm{FEV}_{1} / \mathrm{FVC}$ ratios and $\mathrm{FEV}_{1}$ between ages 21 and 38 years and mean eosinophil counts between ages 21 and 38 .

Participants reporting asthma at any age between 21 and 38 are indicated by cross symbols and dashed lines. a) The coefficient for change in $\mathrm{FEV}_{1} / \mathrm{FVC}$ ratio for participants without asthma is $-5.6 \%$ per $1 \times 10^{9} / \mathrm{L}$ eosinophils $(\mathrm{p}<0.001)$. For those with asthma, the coefficient is $-4.5 \%$ per $1 \times 10^{9} / \mathrm{L}$ eosinophils $(\mathrm{p}=0.034)$. b) The coefficient for change in $\mathrm{FEV}_{1}$ for participants without asthma is $-0.38 \mathrm{~L}$ per $1 \times 10^{9} / \mathrm{L}$ eosinophils $(\mathrm{p}<0.001)$. For those with asthma, the coefficient is $0.30 \mathrm{~L}$ per $1 \times 10^{9} / \mathrm{L}$ eosinophils $(\mathrm{p}=0.048)$. 


\section{Table 1 Participant characteristics}

\begin{tabular}{|l|l|}
\hline Male $(\mathrm{n} / \mathrm{N}(\%))$ & $495 / 971(51 \%)$ \\
\hline Smoker at 21, 26, 32, or 38 years (n/N (\%)) & $439 / 971(45 \%)$ \\
\hline Pack-years smoking by age 38 (n=439) (median (IQR))* & $12.7(6.9-18.9)$ \\
\hline Asthma at 21, 26, 32, or 38 years (n/N (\%)) & $269 / 971(27 \%)$ \\
\hline Wheeze at 21, 26, 32, or 38 years (n/N (\%)) & $609 / 971(37 \%)$ \\
\hline Atopy at 21 or 32 years (n/N (\%)) & $660 / 959(69 \%)$ \\
\hline Pre-bronchodilator spirometry at age 38 years (n=912) $\dagger:$ & \\
\hline Percent predicted FEV $($ mean (SD)) & $97.4 \%(12.6)$ \\
\hline Percent predicted FVC (mean (SD)) & $103.7 \%(11.8)$ \\
\hline FEV $/$ FVC ratio \% (mean (SD)) & $76.2 \%(6.8)$ \\
\hline Post-bronchodilator spirometry at age 38 years (n=898) $\dagger:$ & \\
\hline Percent predicted FEV $($ mean (SD)) & $101.6 \%(12.2)$ \\
\hline Percent predicted FVC (mean (SD)) & \\
\hline FEV $/$ FVC ratio \% (mean (SD)) & \\
\hline
\end{tabular}


The table includes 971 surviving participants with at least one eosinophil measurement between 21 and 38 years. *Non-smokers between 21 and 38 years are excluded from analysis of pack-years. $†$ Pregnant women age 38 are excluded from lung function measurements. IQR $=$ interquartile range. 
Table 2 Eosinophil counts at each age and correlations between ages.

\begin{tabular}{|c|c|c|c|c|c|c|}
\hline & \multicolumn{3}{|c|}{ Eosinophil counts at each age } & \multicolumn{3}{c|}{ Spearman correlations between ages (rho) } \\
\hline Age & $\mathrm{n}$ & Geometric Mean & $95 \%$ CI & 21 & 26 & 32 \\
\hline 21 & 773 & 0.21 & $0.20,0.22$ & & & \\
\hline 26 & 849 & 0.19 & $0.18,0.20$ & 0.579 & & \\
\hline 32 & 866 & 0.20 & $0.19,0.21$ & 0.533 & 0.662 & \\
\hline 38 & 898 & 0.19 & $0.19,0.20$ & 0.498 & 0.552 & 0.642 \\
\hline
\end{tabular}

Excludes pregnant women at each age. Spearman correlations between ages are all statistically significant $(\mathrm{p}$ values $<0.0001)$ 


\section{Table 3 Predictors of blood eosinophil counts}

\begin{tabular}{|l|l|l|l|}
\hline & Coeff & $95 \%$ CI & $\mathrm{P}$ \\
\hline Male Sex & 0.016 & $-0.030,0.062$ & 0.490 \\
\hline Age (yrs) & -0.002 & $-0.003,0.000$ & 0.059 \\
\hline Current Smoker & 0.080 & $0.044,0.116$ & $<0.001$ \\
\hline Atopic sensitisation & 0.075 & $0.024,0.126$ & 0.004 \\
\hline Adult asthma (21 to 38) & 0.164 & $0.099,0.230$ & $<0.001$ \\
\hline Childhood asthma (9 to 13) & 0.071 & $0.001,0.141$ & 0.047 \\
\hline Inhaled corticosteroid use & 0.081 & $0.020,0.143$ & 0.009 \\
\hline
\end{tabular}

Analyses by a random effects linear regression model using 2888 observations from 815 individuals. Coefficients represent the difference in logeosinophil counts associated with each independent predictor. 
Table 4 Association between eosinophil counts and pre- and post-bronchodilator spirometry in participants with and without asthma.

\begin{tabular}{|c|c|c|c|c|c|c|c|c|c|c|}
\hline & & \multicolumn{3}{|c|}{ FEV1/FVC ratio (\%) } & \multicolumn{3}{|c|}{ FEV $1 \%$ predicted } & \multicolumn{3}{|c|}{ FVC \% predicted } \\
\hline & $\mathrm{n}$ & Coef & $95 \% \mathrm{CI}$ & $\mathrm{p}$ & Coef & $95 \% \mathrm{CI}$ & $\mathrm{p}$ & Coef & $95 \% \mathrm{CI}$ & $\mathrm{p}$ \\
\hline Pre-bronchodila & & & & & & & & & & \\
\hline All participants* & 729 & -0.84 & $-1.24,-0.44$ & $<0.001$ & -1.53 & $-2.26,-0.80$ & $<0.001$ & -0.34 & $-1.04,0.35$ & 0.328 \\
\hline No Asthma & 527 & -0.75 & $-1.18,-0.31$ & $<0.001$ & -1.46 & $-2.29,-0.63$ & $<0.001$ & -0.39 & $-1.20,0.42$ & 0.349 \\
\hline Asthma & 202 & -1.01 & $-1.89,-0.14$ & 0.024 & -1.77 & $-3.29,-0.25$ & 0.023 & -0.38 & $-1.74,0.99$ & 0.587 \\
\hline Post-bronchodil & & & & & & & & & & \\
\hline All Participants* & 722 & -0.95 & $-1.38,-0.51$ & $<0.001$ & -0.87 & $-1.74,-0.01$ & 0.048 & 0.30 & $-0.52,1.11$ & 0.475 \\
\hline No Asthma & 523 & -0.86 & $-1.34,-0.38$ & $<0.001$ & -0.65 & $-1.64,0.35$ & 0.205 & 0.35 & $-0.62,1.32$ & 0.479 \\
\hline Asthma & 199 & -1.26 & $-2.18,-0.35$ & 0.007 & -1.67 & $-3.42,0.07$ & 0.060 & 0.13 & $-1.39,1.65$ & 0.863 \\
\hline
\end{tabular}

Coefficients represent the difference in spirometry values associated with blood eosinophil counts in natural logarithm units. Analyses use spirometry and blood eosinophil data from ages 21,26,32, and 38 years and adjust for pre- or post-bronchodilator spirometry values at age 18, sex, age, inhaled corticosteroid use, childhood asthma at ages 9 to 13 years, and cumulative smoking history. *The All Participants analyses also adjust for reported asthma at any age between 21 to 38 years. 
Table 5 Association between eosinophil counts and pre- and post-bronchodilator spirometry in participants with and without wheeze.

\begin{tabular}{|c|c|c|c|c|c|c|c|c|c|c|}
\hline & & \multicolumn{3}{|c|}{ FEV1/FVC ratio (\%) } & \multicolumn{3}{|c|}{ FEV $_{1} \%$ predicted } & \multicolumn{3}{|c|}{ FVC \% predicted } \\
\hline & $\mathrm{n}$ & Coef & $95 \% \mathrm{CI}$ & $\mathrm{p}$ & Coef & $95 \% \mathrm{CI}$ & $\mathrm{p}$ & Coef & $95 \% \mathrm{CI}$ & $\mathrm{p}$ \\
\hline Pre-bronchodila & & & & & & & & & & \\
\hline All participants* & 738 & -0.91 & $-1.30,-0.51$ & $<0.001$ & -1.63 & $-2.36,-0.91$ & $<0.001$ & -0.33 & $-1.02,0.36$ & 0.345 \\
\hline No wheeze & 269 & -0.94 & $-1.54,-0.34$ & 0.002 & -1.26 & $-2.42,-0.09$ & 0.035 & 0.10 & $-1.02,1.22$ & 0.865 \\
\hline Wheeze & 469 & -0.85 & $-1.37,-0.34$ & 0.001 & -1.94 & $-2.86,-1.01$ & $<0.001$ & -0.69 & $-1.57,0.19$ & 0.122 \\
\hline Post-bronchodila & & & & & & & & & & \\
\hline All Participants* & 728 & -1.03 & $-1.46,-0.60$ & $<0.001$ & -0.97 & $-1.83,-0.10$ & 0.028 & 0.31 & $-0.50,1.11$ & 0.457 \\
\hline No wheeze & 265 & -0.62 & $-1.32,0.08$ & 0.081 & -0.07 & $-1.35,1.49$ & 0.927 & 0.71 & $-0.63,2.04$ & 0.299 \\
\hline Wheeze & 463 & -1.25 & $-1.80,-0.71$ & $<0.001$ & -1.62 & $-2.71,-0.53$ & 0.004 & 0.01 & $-1.02,1.01$ & 0.989 \\
\hline
\end{tabular}

Coefficients represent the difference in spirometry values associated with blood eosinophil counts in natural logarithm units. Analyses use spirometry and blood eosinophil data from ages 21,26,32, and 38 years and adjust for pre- or post-bronchodilator spirometry values at age 18, sex, age, inhaled corticosteroid use, childhood wheeze at ages 9 to 13 , and cumulative smoking history. ${ }^{*}$ The All Participants analyses also adjust for reported wheeze at any age between 21 to 38 years. 